\title{
Development of family and dietary habits questionnaires: the assessment of family processes, dietary habits and adolescents' impulsiveness in Norwegian adolescents and their parents
}

Mona Bjelland ${ }^{1 *}$, Solveig ES Hausken ${ }^{1}$, Ester FC Sleddens², Lene F Andersen ${ }^{1}$, Hanne C Lie ${ }^{3}$, Arnstein Finset ${ }^{3}$, Lea Maes ${ }^{4}$, Elisabeth L Melbye ${ }^{5}$, Kari Glavin ${ }^{6,7}$, Merete W Hanssen-Bauer ${ }^{6}$ and Nanna Lien ${ }^{1}$

\begin{abstract}
Background: There is a need for valid and comprehensive measures of parental influence on children's energy balance-related behaviours (EBRB). Such measures should be based on a theoretical framework, acknowledging the dynamic and complex nature of interactions occurring within a family. The aim of the Family \& Dietary habits (F\&D) project was to develop a conceptual framework identifying important and changeable family processes influencing dietary behaviours of 13-15 year olds. A second aim was to develop valid and reliable questionnaires for adolescents and their parents (both mothers and fathers) measuring these processes.
\end{abstract}

Methods: A stepwise approach was used; (1) preparation of scope and structure, (2) development of the F\&D questionnaires, (3) the conducting of pilot studies and (4) the conducting of validation studies (assessing internal reliability, test-retest reliability and confirmatory factor analysis) using data from a cross-sectional study.

Results: The conceptual framework includes psychosocial concepts such as family functioning, cohesion, conflicts, communication, work-family stress, parental practices and parental style. The physical characteristics of the home environment include accessibility and availability of different food items, while family meals are the sociocultural setting included. Individual characteristics measured are dietary intake (vegetables and sugar-sweetened beverages) and adolescents' impulsivity. The F\&D questionnaires developed were tested in a test-retest (54 adolescents and 44 of their parents) and in a cross-sectional survey including 440 adolescents (13-15 year olds), 242 mothers and 155 fathers. The samples appear to be relatively representative for Norwegian adolescents and parents. For adolescents, mothers and fathers, the test-retest reliability of the dietary intake, frequencies of (family) meals, work-family stress and communication variables was satisfactory (ICC: 0.53-0.99). Barratt Impulsiveness Scale-Brief (BIS-Brief) was included, assessing adolescent's impulsivity. The internal reliability (Cronbach's alphas: $0.77 / 0.82$ ) and test-retest reliability values (ICC: 0.74/0.77) of BIS-Brief were good.

Conclusions: The conceptual framework developed may be a useful tool in guiding measurement and assessment of the home food environment and family processes related to adolescents' dietary habits, in particular and for EBRBs more generally. The results support the use of the F\&D questionnaires as psychometrically sound tools to assess family characteristics and adolescent's impulsivity.

Keywords: Family, Adolescent, Diet, Impulsivity, Questionnaire, Validity, Reliability

\footnotetext{
*Correspondence: mona.bjelland@medisin.uio.no

${ }^{1}$ Department of Nutrition, Faculty of Medicine, University of Oslo, P.O.Box

1046, Blindern, NO-0316 Oslo, Norway

Full list of author information is available at the end of the article
} 


\section{Background}

In a life-course perspective the home environment is the first to shape energy balance-related behaviours (EBRBs) such as dietary habits and physical activity [1,2]. Previous studies have indicated that a positive family system may be part of a process establishing and maintaining beneficial health behaviours through role-modelling, provision of healthy foods and support for engaging in healthy behaviours [3,4]. Earlier Norwegian studies have reported low vegetable intake and high energy intake from added sugar and sugar-sweetened beverages (SSB) in children and adolescents [5-9]. However, there seems to have been a recent decrease in SSB intake among Norwegian 11-13 year olds [10].

Several models and frameworks have been developed, which aim to explain how dietary habits of children and adolescents are related to the home food environment [1,3,11-13]. To our knowledge, however, none of these have applied an ecological framework to understand how processes within the family influence dietary habits in children and adolescents. An ecological perspective implies that behaviours or health outcomes result from the interaction between individual and environmental factors. In adolescence this includes the interplay between individual characteristics (such as gender and impulsivity), family processes (for instance family functioning, cohesion and conflicts) and context characteristics (such as family structure and sociocultural settings) [14]. How intrafamilial processes (e.g. inter-personal relationships like parent-parent and parent-child) and extrafamilial conditions (e.g. cross-level interactions such as conditions of parental work and socio economic status) affect families in fostering the healthy development of children needs to be explored [15]. However, little research has applied such socio-ecological frameworks to understand how parents influence children's EBRBs [16].

Conceptualization of concepts related to the home food environment is needed $[17,18]$. Recently, based on the EnRG framework (Environmental Research framework for weight Gain prevention), Kremers et al. [19] stressed the need for "research that applies measures that have increased validity and comprehensiveness as well as theoretical frameworks that acknowledge the dynamic interplay of types and levels of parental influence on child EBRBs." Additionally, the need for development and validation of methods of how to assess environmental influence on diet has been highlighted by Elinder and Jansson [20]. Kitzmann and Beech [21] have also emphasized the importance of exploring a broader focus on the family context, such as general parenting and family functioning, in the promotion of healthy eating and regulation of unhealthy eating among adolescents.

More recently, it has been acknowledged that few studies have combined personality constructs with environmental factors in the prediction of EBRBs $[19,22]$. In the four factor model of temperament described by Buss and Plomin [23], impulsivity is included along with emotionality, activity and sociability. Impulsiveness can be defined as "a predisposition toward rapid, unplanned reactions to internal or external stimuli without regard to the negative consequences of these reactions to the impulsive individuals or to others" [24]. Sleddens et al. [25] found that parental monitoring of children's snacking was moderated by the impulsivity of the child. To specify, for children with high scores on effortful control and extraversion, monitoring was related to less snacking. Therefore, a child's impulsivity may have important consequences for the development, maintenance and treatment of obesity [26].

In sum, an ecological framework including individual characteristics, intrafamilial processes and extrafamilial conditions, combined with instruments developed to assess these aspects within family units, may be a valuable contribution to explore the role of families in fostering healthy development of children and adolescents. The overall aims of the Family \& Dietary habits project (the F\&D project) were therefore to develop a conceptual framework, applied to understand the family influences upon dietary habits in adolescents. Furthermore, to develop valid and reliable questionnaires measuring these important and changeable family processes potentially influencing dietary behaviours for 13-15 year olds and their parents (both mothers and fathers). It would be too demanding to test the questionnaires on all aspects of adolescents' dietary habits, so two behaviours were selected; vegetable intake representing a healthy eating behaviour to be promoted, and consumption of SSB representing an unhealthy eating behaviour to be regulated. These behaviours were also chosen because they are regarded as important contributors to child health and the prevention of obesity and related chronic diseases [27-29].

The current article presents 1) the development of the conceptual framework and the questionnaires, and 2) the individual characteristics, context and extrafamilial conditions of the study sample to be used for further reliability and validation studies. Measures characterizing intrafamilial processes are not included, except for communication which was reported by adolescents only. The psychometric properties of the Barratt Impulsiveness Scale-Brief (BIS-Brief) in Norwegian 13-15 year olds and their parents for assessing adolescents' impulsivity are also included, as a personality characteristic potentially moderating family processes.

\section{Method}

\section{Framework and questionnaire development}

The process for developing the framework and the F\&D questionnaires is summarized in Figure 1 and described below in four steps. 
Step 1. Preparation of scope and structure

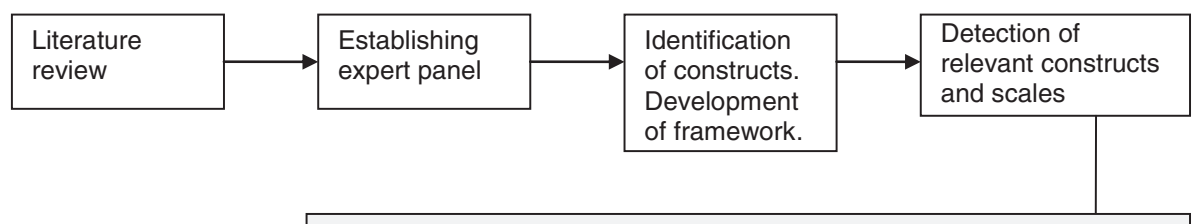

Potential constructs and scales for the questionnaires defined

Step 2. Development of questionnaires; scales and items

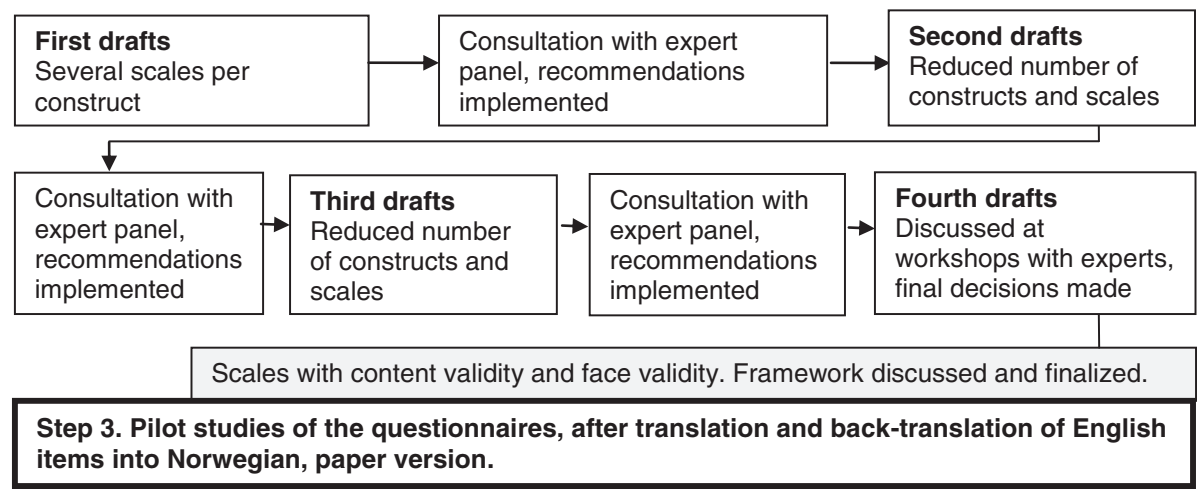

\begin{tabular}{|c|c|c|c|}
\hline $\begin{array}{l}\text { Pre-test: } \\
\text { Cognitive interviewing in } \\
\text { groups similar to the target } \\
\text { groups. Respondents } \\
\text { asked to comment on }\end{array}$ & $\rightarrow \begin{array}{l}\text { Consultation with } \\
\text { expert panel, } \\
\text { recommendations } \\
\text { implemented }\end{array}$ & $\rightarrow$ & $\begin{array}{l}\text { Fifth drafts } \\
\text { Terms and } \\
\text { items } \\
\text { revised } \\
\text { or modified }\end{array}$ \\
\hline
\end{tabular}

Scales with further developed content validity and face validity.

Step 4. Reliability study and cross sectional study by target groups (adolescents, mothers and fathers), web-based version.

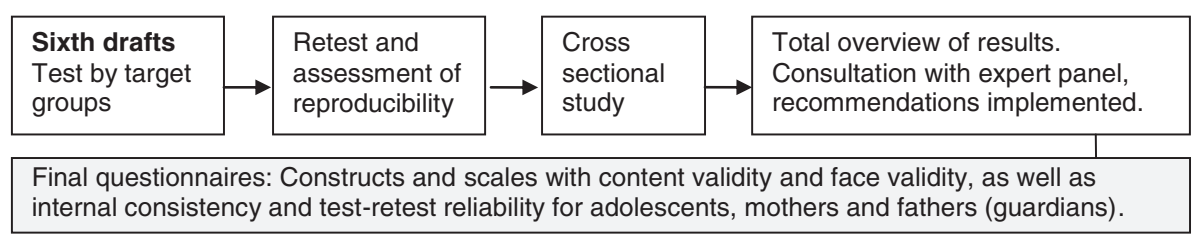

Figure 1 The process applied in the development of questionnaires in the Family \& Dietary habits project.

\section{Step 1: Preparation of scope and structure}

The initial step involved the identification of relevant concepts and the development of a conceptual framework, based an assessment of relevant literature and in collaboration with an expert group. The expert group included five professors, four postdoctoral researchers and one lecturer in different scientific fields related to family processes and dietary habits (nutrition, behavioural sciences, nursing, clinical nutrition, public health, psychology and health promotion).

\section{Definitions}

The following definition of a family was agreed upon: A family is a group consisting of one or two parent(s)/ guardian(s) and one or more children, within the same household. The home food environment is considered to include events (meals/family meals), objects (household availability of food) and social interactions (family processes) experienced by children and parents in the family context, based on previous definitions [30,31]. The family processes in this project include psychosocial 
characteristics as well as more physical characteristics such as accessibility in accordance with Smith et al. [32].

\section{Dietary behaviours}

Intake of SSB was assessed by frequency (six categories, from never/seldom to every weekday) and amount (in glasses, four categories: from 1 glass to 4 glasses or more) for weekdays and by amount for weekends (in glasses, eight categories: from never/seldom to 7 glasses or more) [33]. Vegetable intake was assessed by eight pre-coded frequencies from never to three times or more per day for two questions on raw and cooked vegetables [33].

\section{Target groups}

We hypothesized that the age of the child is one important characteristic, including 13-15 year olds and their parents in our study. In the Norwegian setting, adolescents enter secondary school at the age of 13. Starting secondary school coincides with several shifts in physical, social and cognitive functioning, making this a highly relevant time for studying family processes [34]. After the age of 15 years adolescents begin to experience greater autonomy in decision making [35].

Results from previous studies suggest that the opposite sex parent may play a unique role in influencing adolescent health behaviours, and that there are differences in maternal and paternal parenting practices/styles [36-38]. Gender-specific results are of importance in order to identify underlying causal mechanisms, and therefore the expert group wanted adolescents to report separately for mothers and fathers for relevant constructs related to parenting practices/style.

\section{Step 2: Development of questionnaires; scales and items}

Drafts of the F\&D questionnaires were made based on the literature and the evaluations given by the expert group. During correspondence through e-mail and two workshops the expert group assessed the content and face validity of the instruments [39].

\section{Step 3: Pilot studies of the questionnaires, after translation and back-translation of English items into Norwegian, paper version}

A translation and back-translation of scales/questionnaires available in English were conducted by fluent speakers of the English and Norwegian languages, and a small time-test (paper-versions, 5 adolescents and 2 adults) was conducted. Items were removed or adapted to a Norwegian setting after consulting members of the expert group. A pre-test was conducted in three separate groups, each consisting of three mothers, three fathers and five 13-year-olds, two boys and three girls. Cognitive interviewing was conducted to ensure that adolescents and parents understood the instructions, items and response scales. Moreover, the pre-test consisted of a discussion of whether respondents understood particular words/phrases as intended, and discussion of items identified as complex. Members of the expert group were consulted regarding removal or adaption of items based on the pre-test.

After the pre-test, a pilot study was conducted. It included a time test and a written evaluation of paperversions of the full $F \& D$ questionnaires by 17 adolescents (13 years of age; 9 girls, 8 boys) and 14 parents ( 9 mothers, 5 fathers). The participants were asked to report if there were any questions or statements perceived as particularly unclear/difficult to answer, if any questions or statements should be moved to another part of the questionnaire, and if anything important or relevant was missing. When time testing the paper version of the F\&D questionnaires, the adolescent questionnaire was completed in about 25-45 minutes (average time: $36 \mathrm{mi}$ nutes) $(\mathrm{n}=17)$, and the parental questionnaires in about 20-45 minutes (average time: mothers 30 minutes, fathers 23 minutes) $(\mathrm{n}=14)$.

\section{Step 4: Reliability study and cross-sectional study in the target groups (adolescents, mothers and fathers), web-based version}

All participants were recruited through a convenience sample of five secondary schools - one in the county of Oslo and four in the neighbouring county of Akershus. In total, 1136 adolescents were invited to participate in the cross-sectional study, of which 440 adolescents (13-15 year olds, 39\%) and 397 of their parents (242 mothers (55\%) and 155 fathers (35\%)) participated. Of these, 204 were invited to participate in a test-retest of the web-based versions of the full F\&D questionnaires, and 54 adolescents $(26 \%)$ and 44 of their parents (33 mothers and 11 fathers) participated. The test and retest were conducted 10-14 days apart. The participants were rewarded by providing a small money contribution for the school class (e.g. for school trips). Informed parental consent was obtained from all participants. The webbased F\&D questionnaires were mainly comprised of questions with pre-coded answer categories and the data collections took place at school. Information about how to access the web-based parental questionnaires, one for each parent, was brought home by the adolescent. Most parents provided their e-mail address on the consent form, and thus the information was also sent by e-mail. One e-mail reminder was sent to parents. The Norwegian Social Science Data Services has approved the study and The Regional Committees for Medical and Health Research Ethics has been informed, but no approval was needed. 


\section{Data analysis}

The characteristics of the cross-sectional samples are presented as proportions (demographic variables), means and standard deviations (SD) (behavioural, meals, stress and communication variables). Intra-class correlation coefficient analyses (ICC, a two-way random effects single measure) were used to assess the test-retest reliability. The ICCs were classified as follows: "excellent" $(\geq 0.81)$, "good" (0.61 - 0.80), "moderate" (0.41 - 0.60), 'poor' $(\leq 0.40)[40,41]$. Because the calculation of the ICC depends on the existence of the variability in answers [42], we also calculated percentage agreement for the cases with ICC below 0.5, with criteria established as "excellent" (90\% - 100\%), "good" (75\% - 89\%), "moderate" (60\%-74\%), or "poor" (<60\%) [40].

For the BIS-Brief, Corrected Item-Total Correlation (CITC) and Cronbach's alpha were used to assess the internal reliability of the construct. CITC $>0.30$ were considered good, and $<0.15$ were considered unreliable since they would indicate lack of homogeneity of the items within a scale [43]. Cronbach's alpha was classified as $>0.70=$ "acceptable" and $>0.80=$ "preferable" [44]. Confirmatory factor analysis (CFA) was used to test whether the impulsivity data using the BIS-Brief would fit a hypothesized measurement model based on theory and previous analytic research. Acceptable CFA model fits were Root Mean Square Error of Approximation (RMSEA) $<0.06$ 0.08 and Comparative Fit Index (CFI) $\geq 0.95$ [45].

The descriptive and reliability analyses were performed using $\mathrm{IBM}^{\bullet} \mathrm{PASW}^{\circ}$ Statistics, version 20.0 (IBM Corp.,
Somers, New York, USA). The $\mathrm{IBM}^{\circ} \mathrm{SPSS}^{\circ}$ Amos (IBM Corp., Somers, New York, USA) was used for conducting the CFA.

\section{Results}

\section{Ecological framework}

Based on models/frameworks, literature, inputs from the expert group, and the definitions and aims presented above, an ecological framework was developed describing the different levels and constructs included in the F\&D questionnaires (Figure 2). The rationale for including these constructs and levels is described below.

Recent literature points to the importance of investigating more general measures of family functioning as contexts that can enhance or limit the effectiveness of family-based interventions $[21,38]$. We therefore included measures of family functioning, cohesion, conflict and communication. Two important factors at the parental level are parenting style (a set of attitudes that create a certain emotional climate) and parenting practices (specific behaviours defined by specific socialization goals) $[21,46]$. General parenting determines the context of behaviour specific parenting [46], while specific examples of parenting practices include pressure to eat, restriction, monitoring of the child's food intake, and the use of rewards for food consumption [47].

Another important factor is family meals. The frequency of shared family meals is significantly related to a healthier dietary pattern in children and adolescents $[48,49]$. Moreover, the presence of at least one parent at

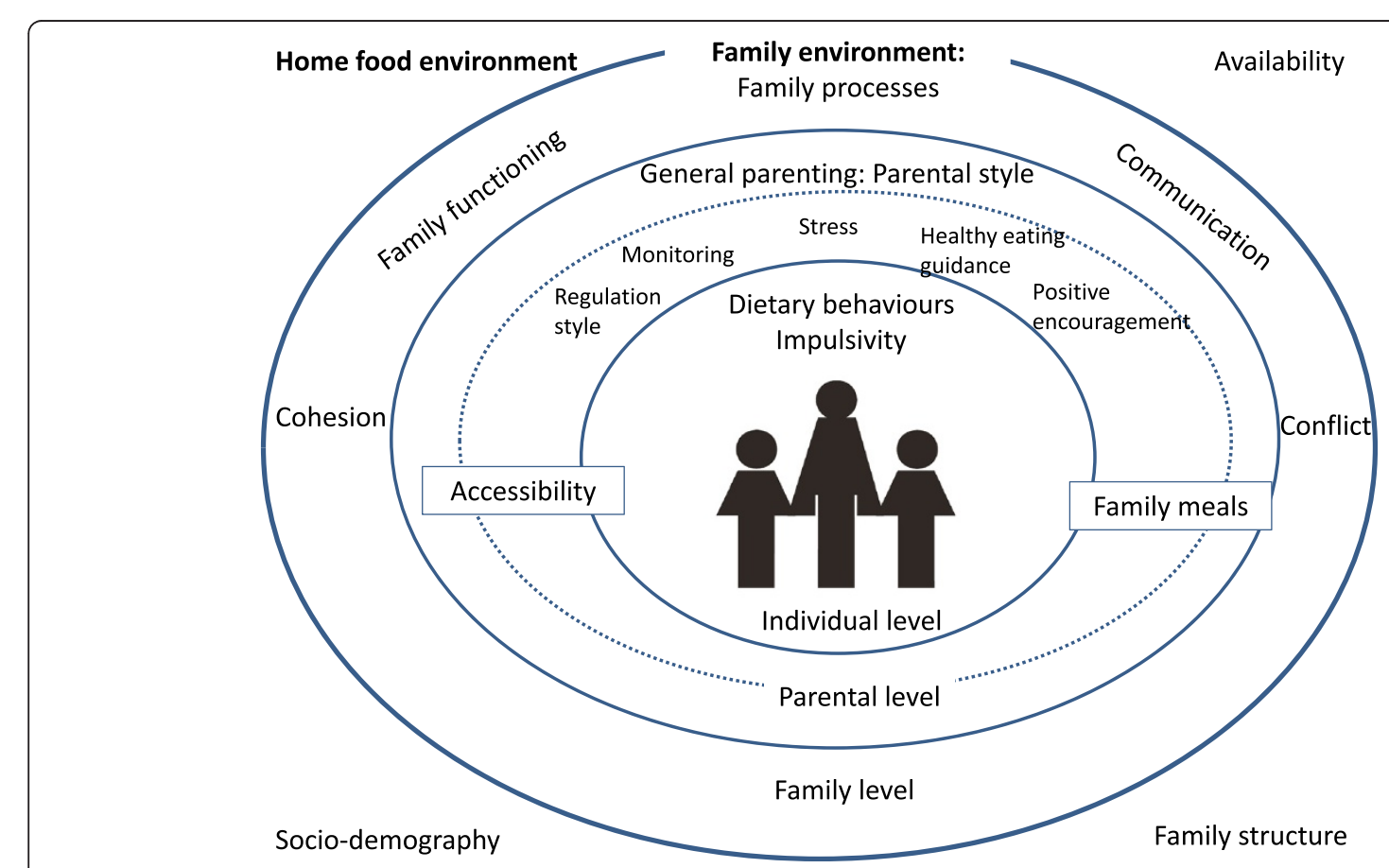

Figure 2 The ecological framework developed in the Family \& Dietary habits project. 
meals is reported to be positively associated with a higher consumption of fruit and vegetables [50]. The relevance of the physical home environment (e.g. availability and accessibility) has been confirmed in several reviews [51-53]. Availability concerns whether foods of interest are present in an environment, while accessibility concerns whether these foods are available in a form, location, and time that facilitates their consumption [54]. Impulsivity is positively associated with several facets of unhealthy eating [55] and weight [56]. Moreover, people who are impulsive tend to be worse at inhibiting and controlling their responses to signals, one of which is the tendency to eat [55]. Adolescent's impulsivity, assessed by BIS-Brief [57], was included at the individual level as a potential moderator of family processes that may influence dietary behaviours $[55,56]$. The BIS-Brief is a short one-dimensional version of the original BIS-11 version [46].

\section{The F\&D questionnaires}

The constructs included in the F\&D questionnaires are presented in Table 1 by the order as in the questionnaires, including references to the original scales. Most of the scales/questionnaires included were from previous studies [25,33,57-67] with the following adaptations for the F\&D questionnaires.
The original Comprehensive Feeding Practices Questionnaire (CFPQ) [68] was developed for parents of children aged 2-8 years. It consists of 49 items representing 12 dimensions (subscales), each including 3-8 items. Initial testing of the CFPQ with parents of older children in a Norwegian setting indicated that the instrument, with some small modifications, was a valid tool for measuring multiple parental feeding practices with parents of 10-12 year olds [69]. However, Haszard et al. [63] performed a CFA on the CFPQ in a large, diverse sample $(n=1013)$ of New Zealand parents of children aged 4-8 years. The results showed that the original twelve-factor model (49 items) was not a good fit and that several factors were strongly inter-correlated. A subsequent CFA yielded five scales of interest (32 items): healthy eating guidance ( 9 items), monitoring ( 4 items), parent pressure (7 items), restriction (8 items) and child control (4 items). Two of the scales were included in our questionnaires (healthy eating guidance and monitoring).

Additionally, Dave et al. [62] have developed a measure of parent-reported social support (instrumental and emotional) for children's fruit and vegetable intake, identifying four subscales; positive encouragement, negative role modelling, discouragement to eat fruit and vegetables and reinforcement. We modified the positive encouragement

Table 1 The constructs included in the questionnaires within the Family \& Dietary habits project

\begin{tabular}{|c|c|c|c|}
\hline \multirow[t]{2}{*}{ Constructs in the questionnaires } & \multicolumn{2}{|l|}{ Number of items } & \multirow[t]{2}{*}{ Reference } \\
\hline & Adolescents & Parents & \\
\hline Socio-demography & 10 & 11 (2 routed) & Lien et al. [33] \\
\hline Meals; Breakfast, dinner and family meals & 6 & & Lien et al. [33] \\
\hline Dietary intake; Vegetables and SSB (amount) & \multicolumn{2}{|c|}{$\begin{array}{l}38 \text { ( } 2 \text { vegetables, } 36 \text { SSB:12 frequency/12 amount week days, } \\
12 \text { amount weekend) }\end{array}$} & Lien et al. [33] \\
\hline Accessibility; Vegetables and SSB & \multicolumn{2}{|c|}{25 (16 accessibility, 9 accessibility/availability) } & Lien et al. [33], Sirard et al. [58] \\
\hline Availability*; Vegetables and SSB & - & 24 & Lien et al. [33], Hearn et al. [65] \\
\hline Family meals (priority, atmosphere, structure) & 9 & & Fulkerson et al. [59] \\
\hline Activities during meals (breakfast, dinner) & 8 & & Fulkerson et al. [59] \\
\hline Communication* & 3 & - & Tabak et. al [60] \\
\hline Family assessment devise (general functioning) & 12 & & Ridenour et al. [61] \\
\hline Family environment scale (cohesion/conflict) & 17 & & Moos and Moos [67] \\
\hline Work-family stress* & - & 3 & Bauer et al. [64] \\
\hline Positive encouragement: Vegetables & 10 ( 5 for mother and 5 for father) & 10 (5 routed) & Dave et al. [62] \\
\hline $\begin{array}{l}\text { Comprehensive Feeding Practices Questionnaire } \\
\text { (healthy eating guidance/monitoring) }\end{array}$ & 26 (13 for mother and 13 for father) & 17 (2 routed) & Haszard et al. [63] \\
\hline Parental style of regulation: SSB, sweets, snacks & 30 (15 for mother and 15 for father) & 15 & Vansteenkiste et al. [66] \\
\hline $\begin{array}{l}\text { Comprehensive General Parenting Questionnaire } \\
\text { (nurturance, structure, behavioural control, } \\
\text { overprotection, coercive control) }\end{array}$ & 98 (49 for mother and 49 for father) & 49 & Sleddens et al. [70] \\
\hline Brief Barratt Impulsiveness Scale & 8 & & Steinberg et al. [57] \\
\hline Weight and height & 2 & & Lien et al. [33] \\
\hline
\end{tabular}

*Adolescents or parents only. Routed: items/questions following specific answer categories. SSB: Sugar sweetened beverages. 
subscale to cover intake of vegetables only [62]. Moreover, when parents reported that they never or seldom encourage their child, a follow-up question with three response options was given; not necessary (due to high intake), not important to me (attitude) or my child is old enough to decide him-/herself (child's autonomy). For healthy eating guidance, monitoring and positive encouragement, both the adolescent perspective (reporting both for the mother and the father) and the parental perspective (from both mothers and fathers) were included.

The parental feeding practices included in our study are practices that could be recommended to promote healthy dietary behaviours; meaning healthy eating guidance, monitoring and positive encouragement. Because we had to limit the number of questions/statements in the questionnaires, other parenting practices were excluded in the F\&D project.

The assessment of parental style of regulation was based on work by Vansteenkiste et al. [66], who developed a measure for parental autonomy-supportive and controlling style in the domain of eating regulation. A modified version assessing an autonomy-supportive, covertly and overtly controlling style in regulation of SSB, sweets and fatty/salty snacks was used in our study. Statements dealing with the way the mother and father regulate intake of SSB, sweets and fatty/salty snacks were presented for the adolescents and the parents. The participants were asked to indicate for each of the statements to what extent it applied to the mother/father on a 5-point scale.

The Comprehensive General Parenting Questionnaire (CGPQ) was systematically developed by Sleddens et al. [70]. First, an item bank of existing parenting measures was created assessing five key parenting constructs: nurturance, structure, behavioural control, overprotection and coercive control. Then caregivers of 5-13 year olds in the Netherlands, Belgium and United States completed an online survey. Factor analyses and Item-Response Modelling techniques were used to assess the underlying parenting constructs and for item reduction. After adding additional questions for better coverage of some subfactors, this resulted in an 85 -item questionnaire. We included a 49-item version of the CGPQ, modified from the 85-item CGPQ by the developers [70], assessing the adolescent perspective (reporting both for the mother and the father) and the parental perspective (from both mothers and fathers). Adolescents and parents were asked to respond to statements about general parenting using a 5-point Likert scale ranging from 1 (strongly agree) to 5 (strongly disagree).

Finally, the Family Environment Scale is composed of 10 subscales that measure actual, preferred, and expected family social environments [67]. To limit the number of questions/statements in the questionnaires, we only included the subscales cohesion and conflict, based on recommendations from the expert group. The item "Family members sometimes hit each other" from the original conflict scale was removed because hitting children is forbidden by law in Norway. This was the only item removed from an original scale included in the questionnaires developed as part of the F\&D project.

\section{Study sample characteristics}

Characteristics of the cross-sectional study sample and the test-retest sample (adolescents and parents) are presented in Tables 2 and 3. The adolescents were on average 14.3 (0.6) years and the genders were equally divided. Most of the adolescents lived together with both parents, while $15.7 \%$ lived with only/mostly the mother or father. In total $66.2 \%$ of the adolescents had parents with higher education ( $\geq 13$ years), and $9.1 \%$ were not ethnic Norwegians (meaning that both parents were born in another country than Norway) [71]. The proportions of girls and highly educated parents were higher in the test-retest sample than in the cross-sectional sample. The distribution of ethnicity and average age was about the same for the mothers and the fathers, while there were more fathers of boys participating compared to fathers of girls. Most of the parents participating lived with the child the whole time while there were a higher proportion of fathers living together with the child's mother than vice versa. The proportion of fathers working full-time was higher compared to mothers, while a higher proportion of mothers worked part-time (Table 2). There was a higher proportion of parents of girls in the testretest sample than in the cross-sectional sample. For both adolescents and parents the consumption of SSB (soft drink and cordials with sugar) was low (mean daily intake on week days was $\leq 1.5 \mathrm{dl} /$ day), and the intake of vegetables was $\leq 10$ times per week (Table 3 ). The means of breakfast and dinner were $\geq 6$ times per week, while the means of family meal frequencies were lower. The parental perceived work-family stress was low (close to 3 on a scale from 1 (strongly agree) to 4 (strongly disagree) in perceived stress). There were 131 dyads (29.8\%) and 128 triads $(29.1 \%)$ in the cross-sectional study sample.

\section{Measures}

For most of the items measuring intakes, meal frequency, work-family stress and communication the test-retest reliability was good (ICC $>0.61$ ) to excellent $($ ICC $>0.81$ ) (Table 3). For the items with an ICC $\leq 0.50$ the exact/percent agreement was calculated, and ranged from moderate to excellent. For the adolescents the exact agreement for dinner was $96 \%$, for family dinners $59 \%$, for intake of cordials on week days $63 \%$ and for cordials intake on weekend days $62 \%$. For adults the exact agreement for dinner 
Table 2 Characteristics (demographic) for the adolescents and parents in the study sample

\begin{tabular}{lll}
\hline & Adolescents & \\
\cline { 2 - 3 } & $\mathbf{n}^{\dagger}=\mathbf{4 4 0}$ & $\mathbf{n}=\mathbf{5 4}$ \\
\hline Age (mean (SD)) & $14.3(0.6)$ & \\
Gender & & $0.3)$ \\
Boys (\%) & 47.7 & 40.7 \\
Girls (\%) & 52.3 & 59.3
\end{tabular}

\section{Live together with}

Mother and father (\%)

Only/mostly with mother (\%)

$\begin{array}{ll}68.7 & 71.7 \\ 13.0 & 17.0 \\ 2.7 & 1.9 \\ 10.0 & 9.7 \\ 4.1 & 0 \\ 0.9 & 0 \\ 0.5 & 0\end{array}$

Other adults (\%)

\section{Ethnicity*}

Norwegian (\%)

$\begin{array}{ll}90.9 & 88.7 \\ 9.1 & 11.3\end{array}$

Other ethnicity (\%)

Parental educational level

$<12$ years $(\%)$
$13-16$ years $(\%)$
$>16$ years $(\%)$

Age (mean (SD))

\section{Gender of child}

Boys (\%)

Girls (\%)

\section{Ethnicity}

Born in Norway (\%)

Born in other country (\%)

Live together with the child (\%)

The whole time

More than $50 \%$ of the time

Half the time (50\% of the time)

Less than $50 \%$ of the time

Seldom

Live together with the child's mother/father

Yes (\%)

33.8

Live alone (\%)

Live with adult who is not child's parent (\%)

\section{Employment status}

Working full-time (\%)

Working part-time (\%)

Not working for pay (\%)
39.3

26.9

Mothers

$\mathrm{n}^{\dagger}=242$

$44.2(4.5)$

9.3

53.7

Fathers

Parents

$\mathrm{n}^{\dagger}=155$

$\mathrm{n} \#=44$

$45.8(5.5)$

$46.2(4.4)$

56.8

84.1

0

0.6

${ }^{\dagger}$ Adolescents; $\mathrm{n}=417-440$ (\# test-retest sample; $\mathrm{n}=53-54$ ), mothers; $\mathrm{n}=240-242$, fathers; $\mathrm{n}=154-155$ (\# test-retest sample; 43-44) *Other ethnicity: Both parents born in other country than Norway. 
Table 3 Characteristics and intraclass correlation coefficients for the dietary habits, meal frequencies, stress and communication

\begin{tabular}{|c|c|c|c|c|c|c|c|c|}
\hline \multirow{3}{*}{ Dietary intake } & \multicolumn{3}{|c|}{ Adolescents } & \multirow{2}{*}{\multicolumn{2}{|c|}{$\frac{\text { Mothers }}{\mathrm{n}^{\dagger}=242}$}} & \multirow{2}{*}{\multicolumn{2}{|c|}{$\begin{array}{l}\text { Fathers } \\
\mathrm{n}^{\dagger}=155\end{array}$}} & \multirow{3}{*}{$\begin{array}{l}\text { Parents } \\
\mathrm{n}^{+}=44\end{array}$} \\
\hline & \multicolumn{2}{|c|}{$n^{\dagger}=440$} & \multirow{2}{*}{$\begin{array}{l}\mathrm{n}^{\dagger}=54 \\
\mathrm{ICC}\end{array}$} & & & & & \\
\hline & Mean & SD & & Mean & SD & Mean & SD & \\
\hline Soft drink, dl/day, week & 0.6 & $(1.0)$ & 0.58 & 0.1 & $(0.7)$ & 0.5 & $(0.9)$ & 0.88 \\
\hline Soft drink, dl/day, weekend & 2.0 & $(1.7)$ & 0.78 & 0.7 & $(1.1)$ & 1.0 & (1.5) & 0.92 \\
\hline Cordials, dl/day, week & 0.9 & $(1.4)$ & 0.53 & 0.2 & $(0.5)$ & 0.4 & (1.0) & 0.89 \\
\hline Cordials, dl/day, weekend & 0.7 & $(1.0)$ & 0.33 & 0.2 & $(0.6)$ & 0.4 & $(0.9)$ & 0.74 \\
\hline Raw vegetables, times/week & 5.6 & $(4.9)$ & 0.63 & 6.3 & $(4.7)$ & 4.7 & (3.6) & 0.82 \\
\hline Cooked vegetables, times/week & 3.9 & $(2.6)$ & 0.60 & 3.7 & $(2.0)$ & 3.9 & (1.9) & 0.66 \\
\hline Total vegetables, times/week & 9.5 & $(6.4)$ & 0.69 & 10.0 & $(5.7)$ & 8.6 & $(4.7)$ & 0.80 \\
\hline Meal frequencies & Mean & SD & ICC & Mean & SD & Mean & SD & ICC \\
\hline Breakfast, times/week & 6.0 & $(1.9)$ & 0.91 & 6.5 & $(1.5)$ & 6.1 & $(1.9)$ & 0.99 \\
\hline Dinner, times/week & 6.8 & $(0.7)$ & 0.49 & 6.8 & $(0.6)$ & 6.7 & $(0.7)$ & 0.14 \\
\hline Family meals; breakfast, times/week & 4.5 & $(2.6)$ & 0.73 & 4.9 & $(2.3)$ & 4.0 & $(2.4)$ & 0.91 \\
\hline Family meals; dinner, times/week & 6.3 & $(1.3)$ & 0.21 & 6.1 & $(1.3)$ & 5.6 & $(1.4)$ & 0.84 \\
\hline Work-family stress" ${ }^{\#}$ reported by parents only & Mean & SD & ICC & Mean & SD & Mean & SD & ICC \\
\hline $\begin{array}{l}\text { Because of the requirements of my job; - I miss out on home or } \\
\text { family activities that I would prefer to participant in. }\end{array}$ & - & - & - & 3.2 & $(0.9)$ & 2.8 & $(0.9)$ & 0.77 \\
\hline - my family time is less enjoyable or more pressured & - & - & - & 3.3 & $(0.7)$ & 3.1 & $(0.7)$ & 0.71 \\
\hline $\begin{array}{l}\text { Working leaves me with too little time or energy to be the kind } \\
\text { of parent I want to be }\end{array}$ & - & - & - & 3.1 & $(0.8)$ & 2.9 & $(0.8)$ & 0.31 \\
\hline Communication* - reported by adolescents only & Mean & SD & ICC & Mean & SD & Mean & SD & ICC \\
\hline Your mother & 1.7 & $(0.8)$ & 0.69 & - & - & - & - & - \\
\hline Your father & 2.1 & $(0.9)$ & 0.72 & - & - & - & - & - \\
\hline Your sibling(s) & 2.3 & $(1.0)$ & 0.65 & - & - & - & - & - \\
\hline
\end{tabular}

${ }^{\dagger} \mathrm{n}$ vary slightly; Adolescents $\mathrm{n}=401-440$, mothers: $n=217-242$, fathers: $n=147-155$. Intraclass correlation coefficient, ICC: Adolescents $n=50-54$, parents: $n=39-44$. \#Strongly agree (1) to strongly disagree (4), mothers; $n=217-218$, fathers; $n=147$ : not answered by those who do not have a paid job.

*Very easy (1) to very difficult (4). Those who do not have or do not see this person(s) are excluded.

was $84 \%$ and for work-family stress ("Working leaves me with too little time or energy to be the kind of parent I want to be") it was $64 \%$ (data not shown).

The mean for adolescent self-rated impulsivity (Additional file 1) was 2.00 (SD 0.49) on a scale ranging from rarely/never (1) to almost always/always (4). The means for the parents' report were 1.93 (SD 0.47) for mothers and 1.98 (SD 0.47) for fathers, respectively. For all three groups (adolescents, mothers, and fathers) the values of CITC were good $(>0.30)$. The Cronbach's alpha was considered acceptable for adolescents and parents $(>0.70)$. The test-retest reliability of BIS-Brief for the three groups was good to excellent (ICC $>0.61$ ).

The factor loadings for adolescents, mothers and fathers in the analyses of the BIS-Brief were between 0.38 and 0.79 . The fit indices for adolescents and fathers were not ideal, but acceptable. The model for mothers fitted the data best with the fit indices approaching acceptable CFA model fits (Additional file 2).

\section{Discussion}

As part of the F\&D project, questionnaires for adolescents and their parents (both mothers and fathers) have been developed based on a conceptual framework. The F\&D questionnaires assess family processes that potentially influence dietary behaviours (intake of vegetables and SSB) in 13-15 year olds. The development process consisted of four steps; (1) preparation of scope and structure, (2) development of the F\&D questionnaires, (3) conducting pilot studies and (4) conducting validation studies using data from a cross-sectional study. As a potential moderator of family processes influencing dietary behaviours, the adolescents' impulsivity was included in our conceptual framework. The study samples appear to be relatively representative for Norwegian adolescents and parents. The test-retest reliability of the dietary intake, (family) meals, work-family stress and communication variables was satisfactory, and the internal reliability and test-retest reliability values of BIS-Brief were good. 


\section{Framework and questionnaire development}

The conceptual framework developed as part of the F\&D project builds on the model of home food environment pertaining to childhood obesity by Rosenkranz and Dzewaltowski [1] and the EnRG framework by Kremers et al. [22], but is presented as an ecological framework $[14,15]$. The ecological framework allows researchers, parents and policy makers to conceptualize the home food environment and conditions that influence adolescents' food choices within this environment. Furthermore, it illustrates the reciprocity among levels and the interrelationships among processes within the family. Finally, the framework can be applied to first understand the causes of adolescents' dietary habits (i.e. determinant analysis) and then to develop strategic responses that bring about changes in these determinants. The F\&D questionnaires developed were tested in a larger survey including multiple existing scales and questionnaires assessing individual characteristics, intrafamilial processes and extrafamilial conditions. Results from this assessment are currently being prepared for publication. The F\&D project is unique in its attempt to incorporate several of these concepts into a comprehensive framework to disentangle the complex mechanisms of family influences on adolescents' dietary habits.

\section{The study sample}

Based on the characteristics measured in our study, the adolescents in the cross-sectional study seem to be relatively representative for Norwegian adolescents. When comparing with the national representative 13- and 15 year olds in the Norwegian sample of the 2009/2010 HBSC-study [72], the proportions of adolescents reporting living with both parents/single parent and eating breakfast every (week)day is about the same as in the F\&D sample. The proportions of adolescents in the F\&D sample who found it very easy/easy to talk to their mother or father about things that really bother them is somewhat higher compared to the HBSC sample, as is the adolescents' daily intake of vegetables. This might be related to the parental education level as the level within the F\&D sample ( $66 \%$ having $\geq 13$ years of education) is higher than for a national representative sample of adults aged $40-49$ (37\% having $\geq 13$ years of education) [73]. In general, immigrants account for about $12 \%$ of the Norwegian population, while the proportion of immigrants in the recruitment area for the F\&D-project is higher (16-17\%) [74,75]. However, the proportion of immigrants in the F\&D sample of adolescents and adults is closer to the national level (9-13\%). The proportion of adults in the F\&D sample working full time is higher than for Norwegian adults at a national level, which may be related to the high educational level [76]. Workfamily stress reported in the F\&D sample is comparable to the work-to-family conflict level reported in another Norwegian study [77]. Taken together, the sample of adolescents in the F\&D sample have higher educated parents compared to the general population, but otherwise the F\&D samples seem relatively representative for Norwegian adolescents and parents.

The test-retest reliability (ICCs) for the adolescents' intake of raw and cooked vegetables is comparable to those found for 11 year olds in the same geographic area in 2007 [78]. The ICCs for soft drink consumption were higher, while the reliability was lower for the assessment of cordial consumption, compared to the previous study [78]. The parental ICCs for beverage intakes were a bit lower compared to the mothers and fathers of the 11 year olds, while the reliability of the measures related to intake of vegetables was higher [78]. For both adolescents and parents the ICCs in our study were higher for the frequencies of breakfast and family breakfast compared to the cross European ENERGY study, including Norwegian 10-12 year olds and their parents [40,79]. The ENERGY study did not include questions about dinner. The ICCs for the work-family stress items are comparable to the test-retest reliability reported by Bauer et al. [64]. No reliability results are available for the measure of communication, but according to Tabak et al. [60] this measure has been "used and validated in numerous national and international studies as a good measure of the respondent's relationship with each of their parents". This is in accordance with the results from our study, showing good test-retest reliability.

Several Norwegian studies have been published related to impulsivity and diagnosis/ conditions like ADHD and self-harm. However, only one study was identified assessing impulsivity in a representative group of Norwegian adolescents (aged 14-17 years) and adolescents from six other countries [80]. The mean score for adolescents in all the seven countries indicated that they "sometimes" were impulsive, which is comparable to our mean which equals "occasionally".

No other studies presenting test-retest reliability or conducting CFA for BIS-Brief in adolescents have been identified. Two studies report results from CFA of the full BIS 11-version in Chinese [81] and Italian [82] adolescents aged 13-19 years. The CFI [45] is one indicator of model fit which can be used to compare results across studies. For the adolescents in our study $\mathrm{CFI}=0.73$, which was close to the results in the Chinese study (CFI=0.77/ 0.78), and higher than the CFI for the one-dimensional model in the Italian study (CFI=0.48).

\section{Strengths and limitations}

The strengths of the questionnaires developed through the F\&D project is the conceptual framework that 
acknowledges the dynamic interplay of types and levels of the home food environment and parental influence, derived from previous solid models and frameworks. Moreover, the F\&D questionnaires include the same questions for both adolescents', mothers and fathers, giving the unique opportunity to explore associations between family processes and dietary behaviours, bidirectional relationships and gender dyads. The main limitations of the questionnaires developed are the length and the assessment of only two dietary behaviours. To be able to assess relevant family processes, several scales/questionnaires need to be included, extending the length of the F\&D questionnaires. The choice of dietary behaviours is based on dietary challenges among Norwegian adolescents and may vary by country and age groups. Furthermore, the generalizability of future findings may be somewhat limited to semi-urban and highly educated families, such as those living in the southeastern region and areas surrounding the largest cities in Norway. The pre-test, pilot and test-retest were conducted at one school in a high socio-economic area which might have affected the results to some degree. Despite these limitations, the F\&D questionnaires appear to be psychometrically sound tools to assess family characteristics and adolescents' impulsivity.

\section{Conclusion}

The conceptual framework developed as part of the F\&D project may be a useful tool in guiding measurement and assessment of the home food environment and the family processes related to adolescents' dietary habits. The F\&D questionnaires are developed to cover all these aspects, including several important and changeable factors that potentially influence adolescents' intake of SSB and vegetables. The presented characteristics of the study sample indicate that findings from this study may be applicable to semi-urban and highly educated families. The evaluation of the BIS-Brief in 13-15 year olds and their parents suggests that this scale can be used to assess adolescents' impulsivity in future studies. The next steps are to explore associations between family processes and the dietary behaviours, bidirectional relationships and gender dyads/triads related to the home food environment. In the long term, it will be interesting to test the questionnaires in assessing family processes longitudinally.

\section{Additional files}

Additional file 1: BIS-Brief; means (SD), Cronbach's alpha and intraclass correlation coefficients for the study sample.

Additional file 2: Factor loadings (confirmatory factor analysis) for BIS-Brief in the study sample.

\section{Competing interests}

The authors declare that they have no competing interests.

\section{Authors' contributions}

All authors are responsible for the reported research. M.B. worked on the statistical analyses, wrote the first draft of the manuscript and made the greatest contribution to the paper. S.E.S.H prepared and conducted the pre-test, pilot and data collection. All authors participated in the development of the framework and the questionnaires. All authors provided critical revision of the paper, and read and approved the final manuscript.

\section{Acknowledgements}

Many thanks go to the adolescents, mothers and fathers, and to the project staff participating in the data collection. Thanks to Anne Feren for help with Figure 1.

\section{Funding}

The Family \& Dietary habits project was funded by the Norwegian Research Council [grant number 213857/H10].

\section{Author details}

'Department of Nutrition, Faculty of Medicine, University of Oslo, P.O.Box 1046, Blindern, NO-0316 Oslo, Norway. ²Department of Health Promotion, Nutrition and Toxicology Research Institute Maastricht (NUTRIM), Maastricht University Medical Center+, Maastricht, The Netherlands. ${ }^{3}$ Department of Behavioural Sciences in Medicine, Faculty of Medicine, University of Oslo, Oslo, Norway. ${ }^{4}$ Public Health Department, Ghent University, Ghent, Belgium. ${ }^{5}$ University of Stavanger, UiS Business School, Stavanger, Norway.

${ }^{6}$ Department of Nursing, Faculty of Health Sciences, Oslo and Akershus University College of Applied Sciences, Oslo, Norway. ${ }^{7}$ Department of Nursing, Diakonova University College, Oslo, Norway.

Received: 27 January 2014 Accepted: 8 October 2014

Published online: 15 October 2014

\section{References}

1. Rosenkranz RR, Dzewaltowski DA: Model of the home food environment pertaining to childhood obesity. Nutr Rev 2008, 66:123-140.

2. Brug J, te Velde SJ, Chinapaw MJ, Bere E, de Bourdeaudhuij I, Moore H, Maes L, Jensen J, Manios Y, Lien N, Klepp Kl, Lobstein T, Martens M, Salmon J, Singh AS: Evidence-based development of school-based and familyinvolved prevention of overweight across Europe: the ENERGY-project's design and conceptual framework. BMC Public Health 2010, 10:276.

3. Kitzman-Ulrich H, Wilson DK, St George SM, Lawman H, Segal M, Fairchild A: The integration of a family systems approach for understanding youth obesity, physical activity, and dietary programs. Clin Child Fam Psychol Rev 2010, 13:231-253.

4. Vereecken C, Haerens L, De Bourdeaudhuij I, Maes L: The relationship between children's home food environment and dietary patterns in childhood and adolescence. Public Health Nutr 2010, 13:1729-1735.

5. Andersen LF, Overby N, Lillegaard IT: Intake of fruit and vegetables among Norwegian children and adolescents [In Norwegian]. TidsskrNor Laegeforen 2004, 124:1396-1398.

6. Bere $\mathrm{E}, \mathrm{Klepp} \mathrm{KI}$ : Correlates of fruit and vegetable intake among Norwegian schoolchildren: parental and self-reports. Public Health Nutr 2004, 7:991-998.

7. Yngve A, Wolf A, Poortvliet E, Elmadfa I, Brug J, Ehrenblad B, Franchini B, Haraldsdottir J, Krolner R, Maes L, Pérez-Rodrigo C, Sjostrom M, Thórsdóttir I, Klepp Kl: Fruit and vegetable intake in a sample of 11-year-old children in 9 European countries: The Pro Children Cross-sectional Survey. Ann Nutr Metab 2005, 49:236-245.

8. Bjelland $M$, Lien $N$, Grydeland $M$, Bergh $1 H$, Anderssen SA, Ommundsen $Y$, Klepp Kl, Andersen LF: Intakes and perceived home availability of sugarsweetened beverages, fruit and vegetables as reported by mothers, fathers and adolescents in the HEIA (HEalth In Adolescents) study. Public Health Nutr 2011, 14:2156-2165.

9. Overby NC, Lillegaard IT, Johansson L, Andersen LF: High intake of added sugar among Norwegian children and adolescents. Public Health Nutr 2004, 7:285-293. 
10. Stea TH, Overby NC, Klepp Kl, Bere E: Changes in beverage consumption in Norwegian children from 2001 to 2008. Public Health Nutr 2012, 15:379-385

11. Gattshall ML, Shoup JA, Marshall JA, Crane LA, Estabrooks PA: Validation of a survey instrument to assess home environments for physical activity and healthy eating in overweight children. Int J Behav Nutr Phys Act 2008, $5: 3$

12. Weber Cullen K, Baranowski T, Rittenberry L, Cosart C, Owens $E_{1}$ Hebert D, de Moor C: Socioenvironmental influences on children's fruit, juice and vegetable consumption as reported by parents: reliability and validity of measures. Public Health Nutr 2000, 3:345-356.

13. Story M, Kaphingst KM, Robinson-O'Brien R, Glanz K: Creating healthy food and eating environments: policy and environmental approaches. Annu Rev Public Health 2008, 29:253-272.

14. Bronfenbrenner U, Crouter AC: The evolution of environmental models in developmental research. In Handbook of Child Psychology: History, Theory and Methods, Volume 1. Edited by Mussen PH, Kessen W. New York: John Wiley; 1983:357-414.

15. Bronfenbrenner U: Ecology of the family as a context for human development: research perspectives. Dev Psychol 1986, 22:723-742.

16. Patrick H, Hennessy E, McSpadden K, Oh A: Parenting styles and practices in children's obesogenic behaviors: scientific gaps and future research directions. Childhood Obes 2013, 9(Suppl 1):S73-S86.

17. Booth SL, Sallis JF, Ritenbaugh C, Hill JO, Birch LL, Frank LD, Glanz K, Himmelgreen DA, Mudd M, Popkin BM, Rickard KA, St Jeor S, Hays NP: Environmental and societal factors affect food choice and physical activity: rationale, influences, and leverage points. Nutr Rev 2001, 59:S21-\$39.

18. Mueller CW: Conceptualization, Operationalization, and Measurement. In The SAGE Encyclopedia of Social Science Research Methods. Edited by Lewis-Beck MS, Bryman A, Lia TF. Thousand Oaks: Sage Publications; 2004.

19. Kremers S, Sleddens E, Gerards S, Gubbels J, Rodenburg G, Gevers D, van Assema P: General and food-specific parenting: measures and interplay. Childhood Obes 2013, 9(Suppl 1):S22-S31.

20. Elinder LS, Jansson M: Obesogenic environments-aspects on measurement and indicators. Public Health Nutr 2009, 12:307-315.

21. Kitzmann KM, Beech BM: Family-based interventions for pediatric obesity: methodological and conceptual challenges from family psychology. J Fam Psychol 2006, 20:175-189.

22. Kremers SP, de Bruijn GJ, Visscher TL, van Mechelen W, De Vries NK, Brug J: Environmental influences on energy balance-related behaviors: a dual-process view. Int J Behav Nutr Phys Act 2006, 3:9.

23. Buss AH, Plomin R: A Temperament Theory of Personality Development. New York: John Wiley \& Sons; 1975.

24. Moeller FG, Barratt ES, Dougherty DM, Schmitz JM, Swann AC: Psychiatric aspects of impulsivity. Am J Psychiatry 2001, 158:1783-1793.

25. Sleddens EFC: Childhood overweight: The influence of parenting on children's energy-balance related behavior. In PhD Thesis. Maastricht University: Department of Health Promotion; 2013.

26. Nederkoorn C, Braet C, Van Eijs Y, Tanghe A, Jansen A: Why obese children cannot resist food: the role of impulsivity. Eat Behav 2006, 7:315-322.

27. Malik VS, Pan A, Willett WC, Hu FB: Sugar-sweetened beverages and weight gain in children and adults: a systematic review and meta-analysis. Am J Clin Nutr 2013, 98:1084-1102.

28. Massougbodji J, Le Bodo Y, Fratu R, De Wals P: Reviews examining sugar-sweetened beverages and body weight: correlates of their quality and conclusions. Am J Clin Nutr 2014, 99:1096-1104

29. Boeing $H$, Bechthold A, Bub A, Ellinger S, Haller D, Kroke A, Leschik-Bonnet E, Muller MJ, Oberritter H, Schulze M, Stehle P, Watzl B: Critical review: vegetables and fruit in the prevention of chronic diseases. Eur J Nutr 2012, 51:637-663.

30. Rijlaarsdam J, Stevens GW, van der Ende J, Arends LR, Hofman A, Jaddoe WW, Mackenbach JP, Verhulst FC, Tiemeier H: A brief observational instrument for the assessment of infant home environment: development and psychometric testing. Int J Methods Psychiatr Res 2012, 21:195-204.

31. Campbell KJ, Crawford DA, Salmon J, Carver A, Garnett SP, Baur LA: Associations between the home food environment and obesitypromoting eating behaviors in adolescence. Obesity (Silver Spring) 2007, 15:719-730
32. Smith EP, Prinz RJ, Dumas JE, Laughlin J: Latent models of family processes in African American families: relationships to child competence, achievement, and problem behavior. J Marriage Family 2001, 63:967-980.

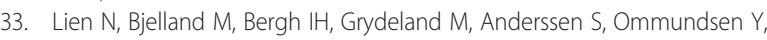
Anderssen SA, Henriksen HB, Randby J, Klepp Kl: Design of a two year comprehensive, multi-coponent school-based intervention to promote healthy weight development amog 11-13 year olds: the HEIA-study. Scand J Public Health 2010, 38(Suppl 5):S38-S51.

34. Burke K, Brennan L, Roney S: A randomised controlled trial of the efficacy of the ABCD Parenting Young Adolescents Program: rationale and methodology. Child Adolesc Psychiatry Ment Health 2010, 4:22.

35. Wray-Lake L, Crouter AC, McHale SM: Developmental patterns in decisionmaking autonomy across middle childhood and adolescence: European American parents' perspectives. Child Dev 2010, 81:636-651.

36. Berge JM, Wall M, Neumark-Sztainer D, Larson N, Story M: Parenting style and family meals: cross-sectional and 5-year longitudinal associations. J Am Diet Assoc 2010, 110:1036-1042.

37. Berge JM, Wall M, Bauer KW, Neumark-Sztainer D: Parenting characteristics in the home environment and adolescent overweight: a latent class analysis. Obesity 2010, 18:818-825.

38. Sleddens EF, Gerards SM, Thijs C, de Vries NK, Kremers SP: General parenting, childhood overweight and obesity-inducing behaviors: a review. Int J Pediatr Obes 2011, 6:e12-e27.

39. Streiner DL, Norman GR: Basic concepts. In Health Measurement Scales - 0 Practical Guide to Their Development and use. New York: Oxford University Press; 2008:5-15.

40. Singh AS, Vik FN, Chinapaw MJ, Uijtdewilligen L, Verloigne M, Fernandez Alvira JM, Stomfai S, Manios Y, Martens M, Brug J: Test-retest reliability and construct validity of the ENERGY-child questionnaire on energy balancerelated behaviours and their potential determinants: the ENERGYproject. Int J Behav Nutr Phys Act 2011, 8:136.

41. Landis JR, Koch GG: The measurement of observer agreement for categorical data. Biometrics 1977, 33:159-174.

42. Muller R, Buttner P: A critical discussion of intraclass correlation coefficients. Stat Med 1994, 13:2465-2476.

43. Nunnally JC, Bernstein $\mathrm{IH}$ : Psychometric Theory. 2nd edition. New York: McGraw-Hill; 1994

44. Field A: Discovering Statistics using IBM SPSS Statistics. 3rd edition. London: SAGE Publications Ltd; 2009.

45. Schreiber JB, Nora A, Stage FK, Barlow EA, King J: Reporting structural equation modeling and confirmatory factor analysis results: a review. J Educ Res 2006, 99:232-337.

46. Darling N, Steinberg L: Parenting style as context: an integrative model. Psychol Bull 1993, 113:487-496

47. Vaughn AE, Tabak RG, Bryant MJ, Ward DS: Measuring parent food practices: a systematic review of existing measures and examination of instruments. Int J Behav Nutr Phys Act 2013, 10:61.

48. Hammons AJ, Fiese $\mathrm{BH}$ : Is frequency of shared family meals related to the nutritional health of children and adolescents? Pediatrics 2011, 127:e1565-e1574.

49. Berge JM: A review of familial correlates of child and adolescent obesity: what has the 21st century taught us so far? J Adolesc Med Health 2009, 21:457-483

50. Videon TM, Manning CK: Influences on adolescent eating patterns: the importance of family meals. J Adolesc Health 2003, 32:365-373.

51. Rasmussen M, Krolner R, Klepp Kl, Lytle L, Brug J, Bere E, Due P: Determinants of fruit and vegetable consumption among children and adolescents: a review of the literature. Part I: Quantitative studies. Int J Behav Nutr Phys Act 2006, 3:22.

52. Baranowski T, Watson K, Missaghian M, Broadfoot A, Cullen K, Nicklas T, Fisher J, Baranowski J, O'Donnell S: Social support is a primary influence on home fruit, $100 \%$ juice, and vegetable availability. J Am Diet Assoc 2008, 108:1231-1235.

53. Verloigne M, Van Lippevelde W, Maes L, Brug J, de Bourdeaudhuij I: Familyand school-based correlates of energy balance-related behaviours in 10-12-year-old children: a systematic review within the ENERGY (EuropeaN Energy balance Research to prevent excessive weight Gain among Youth) project. Public Health Nutr 2012, 15:1380-1395.

54. Cullen KW, Baranowski T, Owens E, Marsh T, Rittenberry L, de Moor C: Availability, accessibility, and preferences for fruit, $100 \%$ fruit juice, and 
vegetables influence Children's dietary behavior. Health Educ Behav 2003, 30:615-626.

55. Farrow CV: Do parental feeding practices moderate the relationships between impulsivity and eating in children? Eat Behav 2012, 13:150-153.

56. Thamotharan S, Lange K, Zale EL, Huffhines L, Fields S: The role of impulsivity in pediatric obesity and weight status: a meta-analytic review. Clin Psychol Rev 2013, 33:253-262.

57. Steinberg L, Sharp C, Stanford MS, Tharp AT: New tricks for an old measure: the development of the Barratt Impulsiveness Scale-Brief (BIS-Brief). Psychol Assess 2013, 25:216-226.

58. Sirard JR, Nelson MC, Pereira MA, Lytle LA: Validity and reliability of a home environment inventory for physical activity and media equipment. Int J Behav Nutr Phys Act 2008, 5:24

59. Fulkerson JA, Neumark-Sztainer D, Story M: Adolescent and parent views of family meals. J Am Diet Assoc 2006, 106:526-532.

60. Tabak I, Mazur J, Granado Alcon MC, Orkenyi A, Zaborskis A, Aasvee K, Moreno C: Examining trends in parent-child communication in Europe over 12 years. J Early Adolesc 2011, 32:26-54.

61. Ridenour TA, Daley J, Reich W: Factor analysis of the family assessment device. Fam Process 1999, 38:497-510.

62. Dave JM, Evans AE, Condrasky MD, Williams JE: Parent-reported social support for child's fruit and vegetable intake: validity of measures. J Nutr Educ Behav 2012, 44:132-139.

63. Haszard JJ, Williams SM, Dawson AM, Skidmore PM, Taylor RW: Factor analysis of the comprehensive feeding practices questionnaire in a large sample of children. Appetite 2013, 62:110-118.

64. Bauer KW, Hearst MO, Escoto K, Berge JM, Neumark-Sztainer D: Parental employment and work-family stress: associations with family food environments. Soc Sci Med 2012, 75:496-504.

65. Hearn MD, Baranowski T, Baranowski J, Doyle C, Smith M, Lin LS, Resnicow $K$ : Environmental influences on dietary behavior among children: availability and accessibility of fruits and vegetables enable consumption. J Health Educ 1998, 29:26-32.

66. Vansteenkiste M, Soenens B, Petegem SV, Duriez B: Longitudinal associations between adolescent perceived degree and style of parental prohibition and internalization and defiance. Developmental Psychology 2014, 50:229-236.

67. Moos RH, Moos BS: Family Environment Scale Manual and Sampler Set: Development, Applications and Research. Received from Mind Garden November 10, 2012. 4th edition. 2009 [http://www.mindgarden.com/ products/fescs.htm]

68. Musher-Eizenman D, Holub S: Comprehensive feeding practices questionnaire: validation of a new measure of parental feeding practices. J Pediatr Psychol 2007, 32:960-972.

69. Melbye EL, Ogaard T, Overby NC: Validation of the comprehensive feeding practices questionnaire with parents of 10-to-12-year-olds. BMC Med Res Methodol 2011, 11:113.

70. Sleddens EF, O'Connor TM, Watson KB, Hughes SO, Power TG, Thijs C, De Vries NK, Kremers SP: Development of the comprehensive general parenting questionnaire for caregivers of 5-13 year olds. Int J Behav Nutr Phys Act 2014, 11:15

71. Vassenden K: Immigrants in Norway, who are they, what are they and how do they live? In [In Norwegian]. Statistics Norway; 1997 [http://www. ssb.no/a/histstat/sa/sa_020.pdf]

72. Social determinants of health and well-being among young people. Health Behaviour in School-aged Children (HBSC) study: international report from the 2009/2010 survey. Europe: World Health Organization; 2012 [http://www.euro.who.int/_data/assets/pdf_file/0003/163857/Socialdeterminants-of-healthand-well-being-among-young-people.pdf]

73. Statistics Norway: The population's education level, 1 October 2012 [http://www.ssb.no/utniv/]

74. Østby L, Høydahl E, Rustad Ø: Immigrants distribution and composition at the municipal level. In [In Norwegian] Statistics Norway; 2013 [http://www. ssb.no/befolkning/artikler-ogpublikasjoner/_attachment/136681?_ts=140 e2a916f8]

75. Statistics Norway: Immigrants and Norwegian-born to immigrant parents, 1 January 2013. [http://www.ssb.no/innvbef/]

76. Næsheim $\mathrm{H}$, Villund O: Part-time work - the differences are equalized? In [In Norwegian]. Statistics Norway; Samfunnsspeilet; 2013 [http:/www.ssb.no/ arbeid-og-lonn/artikler-og-publikasjoner/_attachment/109963?_ts= 13e4016ef48]
77. Hammer TH, Saksvik PO, Nytro K, Torvatn H, Bayazit M: Expanding the psychosocial work environment: workplace norms and work-family conflict as correlates of stress and health. J Occup Health Psychol 2004, 9:83-97.

78. Bjelland M: Obesity prevention targeting Norwegian adolescents; Prevalence rates, determinants and intervention effects by gender, parental education and parent-child associations. In PhD thesis. University of Oslo: Department of Nutrition; 2011.

79. Singh AS, Chinapaw MJ, Uijtdewilligen L, Vik FN, van Lippevelde W, Fernandez-Alvira JM, Stomfai S, Manios Y, van der Sluijs M, Terwee C, Brug J: Test-retest reliability and construct validity of the ENERGY-parent questionnaire on parenting practices, energy balance-related behaviours and their potential behavioural determinants: the ENERGY-project. BMC Res Notes 2012, 5:434.

80. Madge N, Hawton K, McMahon EM, Corcoran P, De Leo D, de Wilde EJ, Fekete S, van Heeringen K, Ystgaard M, Arensman E: Psychological characteristics, stressful life events and deliberate self-harm: findings from the Child \& Adolescent Self-harm in Europe (CASE) Study. Eur Child Adolesc Psychiatry 2011, 20:499-508.

81. Yao S, Yang H, Zhu X, Auerbach RP, Abela JR, Pulleyblank RW, Tong X: An examination of the psychometric properties of the Chinese version of the Barratt Impulsiveness Scale, 11th version in a sample of Chinese adolescents. Percept Mot Skills 2007, 104:1169-1182.

82. Fossati A, Barratt ES, Acquarini E, Di Ceglie A: Psychometric properties of an adolescent version of the Barratt Impulsiveness Scale-11 for a sample of Italian high school students. Percept Mot Skills 2002, 95:621-635.

doi:10.1186/s12966-014-0130-z

Cite this article as: Bjelland et al:: Development of family and dietary habits questionnaires: the assessment of family processes, dietary habits and adolescents' impulsiveness in Norwegian adolescents and their parents. International Journal of Behavioral Nutrition and Physical Activity 2014 11:130.

\section{Submit your next manuscript to BioMed Central and take full advantage of:}

- Convenient online submission

- Thorough peer review

- No space constraints or color figure charges

- Immediate publication on acceptance

- Inclusion in PubMed, CAS, Scopus and Google Scholar

- Research which is freely available for redistribution 